\title{
Effect of Health Educational Intervention on Knowledge and Perceptions of Asthma among Secondary School Students in Ile-Ife, South-West, Nigeria
}

\author{
Article by Ilesanmi, Oluwafemi Temitayo ${ }^{1}$, Adegbenro, Caleb $\mathrm{A}^{2}$, Erhabor, Gregory $\mathrm{E}^{3}$, \\ Olatona, Foluke $\mathrm{A}^{4}$, Adewole, Olanisun $\mathrm{O}^{3}$, Awopeju, Olayemi $\mathrm{F}^{3}$, Adeniyi, Bamidele $\mathrm{O}^{5}$ \\ ${ }^{I}$ Texila American University and Department of Medical Rehabilitation, Obafemi \\ Awolowo University Teaching Hospitals Complex, Ile-Ife, Osun State, Nigeria \\ ${ }^{2}$ Department of Community Health, College of Health Sciences, Obafemi Awolowo \\ University, Ile-Ife, Osun State, Nigeria \\ ${ }^{3}$ Department of Medicine (Respiratory Unit), College of Health Sciences, Awolowo \\ University, Ile- Ife, Osun State, Nigeria. \\ ${ }^{4}$ Department of Community Health and Primary Care, College of Medicine, University of \\ Lagos, Lagos, Nigeria \\ ${ }^{5}$ Department of Internal Medicine (Respiratory Unit), Federal Medical Centre, Owo, Ondo \\ State, Nigeria \\ E-mail:aboundinggrace08@yahoo.com
}

\begin{abstract}
Asthma is a major public health problem among adolescents with significant functional disability. Inadequate knowledge and poor perceptions of the disease are highly contributory to its impact. Patients' education is vital in addressing this challenge. The study assessed the level of knowledge and perceptions of asthma and the impact of asthma health education programme among a group of the secondary school students in Ile-Ife, Nigeria. It is a quasi-experimental design study which used a pre-tested 71-item, purpose designed, self- administered questionnaires to collect information on knowledge and perceptions of the respondents on asthma before and after intervention. Data were collated and analyzed based on descriptive and inferential study design. The results of this study showed that perceptions and knowledge of asthma were poor among the group. There was a significant difference in the pre-test and post-test knowledge and perceptions scores of asthma of the secondary school students in the intervention group following health education programme intervention. In addition, the results showed that there was a significant change in knowledge and perceptions of asthma overtime for the participants in the intervention group, over a period of 1 week, 3 weeks and over a period of 6 weeks. We concluded that health educational intervention has significant positive effect on knowledge and perceptions of asthma among secondary school students in Ile-Ife, Osun State, South West, Nigeria.
\end{abstract}

Keywords: Asthma; Knowledge; Perceptions; Health Educational Intervention.

\section{Introduction}

Asthma is a chronic airway disease characterized by chronic airways inflammation, bronchial hyper-responsiveness and reversible airflow obstruction, resulting in recurrent attacks of wheeze, chest tightness, breathlessness, and cough with sputum production, with varying severity and frequency from person to person (WHO, 2012; Bousquet et al, 2010; Reddel et al, 2009). Asthma constitutes a major functional disability on its sufferers affecting their psychological, physical and social well- being. Asthma is a major health problem among adolescents. Adolescents are defined by the WHO as young people between the age of 10 and 19 years of age. Adolescents with asthma are at higher risk of serious disease complications due to under-appreciation and denial of their disease severity, non-adherence with medications and trigger avoidance, and other risk-taking behaviours such as smoking tobacco or marijuana and using cocaine (Guo et al, 2010; Towns et al, 2009; Bender, 2007). Patients in this age group may not appreciate the danger of poorly controlled asthma. They may deny having a chronic illness, or they may view the treatment plan as interfering with their 
emerging independence as they strive to reach adulthood (Burns et al, 2006). Peers and teachers are known to exert important influences during adolescence. Hence, increasing the knowledge and attitudes of these groups could be expected to influence adolescents with asthma as knowledge, attitudes, and beliefs are recognised as being major determinants of health behaviour, including compliance with therapy (Brooks et al, 1993). Asthma education and prevention remains the greatest opportunity for decreasing asthma incidence, morbidity and mortality (Kintner et al, 2015). All these have been shown to improve through asthma health education intervention among school students (Valeros et al, 2001; Thies et al, 2001). Health education has the potential to help students maintain and improve their health, prevent disease, and reduce health-related risk behaviours (Kann et al, 2007). Health education is any combination of learning experiences designed to help individuals and communities improve their health by increasing their knowledge or influencing their attitude (WHO, 2013).

\section{Significance of study}

There are limited published works on the effect of health educational intervention on knowledge and perceptions of asthma among secondary school students in Nigeria. The outcome of this study provided information on gap in the knowledge and perceptions of asthma among secondary school students in Ile- Ife, Nigeria and the impact of a structured health education on these. Information obtained from this study could also be used by health professionals to implement health prevention programmes relating to asthma. Furthermore, the data collected in the course of the research could serve as baseline for further studies.

\section{Statement of problem}

It is now estimated that over 330 million people of all ages, and all ethnic backgrounds, suffer from asthma and the burden of this disease to governments, health care systems, families, and patients is increasing worldwide (Marsden et al, 2016; GINA, 2014; Vos et al, 2013). Asthma is characterized by a major impact on the lives of affected persons resulting in missed days of school for school children, missed work days characterised by lack of productivity, unplanned childcare, emergency room visits, sleep disorders and fatigue, physical limitations and depression (Kintner et al, 2015). Asthma is a major health problem among adolescents. There is substantial under-diagnosis, poor acceptance of diagnosis, poor compliance to treatment and poor understanding of asthma management among this population (Oluwole et al, 2017; Musa et al, 2014). These have been attributed to inadequate knowledge and wrong perceptions about asthma (Anwar et al, 2008; Bjorksten, 2000). Health education has been suggested as a vital element of the response to the challenge posed by asthma especially in Africa (Braman, 2006; Ndiaye et al, 2004).

Schools have been identified as the prime settings for asthma health education for children and adolescents due to practicality, familiarity with the environment and the magnitude of influence that peers equipped with knowledge exert on themselves which has the potential to reduce morbidity outcomes in asthma (Valeros et al, 2001; Thies et al, 2001). Several school based studies have been conducted to assess the impact of asthma health education programme on students showing significant improvement in their knowledge of asthma, reduction in school absenteeism, improvement in selfefficacy perception and improvement in their quality of life (Cicutto et al, 2013; Bowen, 2013; McGhan et al, 2010; Kintner et al, 2009). Most of these data have come from developed countries and limited to students who have asthma. Little is known about the effect of health education intervention on knowledge and perceptions of asthma among secondary school students in Ile Ife (both with asthma and without asthma). This study is, therefore, directed to assess the effect of health educational intervention on knowledge and perceptions of asthma among secondary school students in Ile- Ife, South- West, Nigeria.

\section{Research questions}

The major research questions for this study include the followings:

1. Is there a difference between the intervention group's knowledge and perceptions of asthma pretest and post-test scores following the health education programme intervention? 
2. Is there a difference in the control group's knowledge and perceptions of asthma pre-test and posttest scores?

3. Do secondary school students' knowledge and perceptions about asthma change over time without receiving the health education programme intervention?

4. Do secondary school students' knowledge and perceptions about asthma change over time following the health education programme intervention?

\section{Research objectives}

1. To determine the level of knowledge of asthma and effect of asthma health education programme among the secondary school students in Ile- Ife, Nigeria.

2. To assess level of perceptions of asthma and effect of asthma health education programme among the secondary school students in Ile- Ife, Nigeria.

3. To provide health education for the secondary school students in the intervention group.

4. Determine the effect of health education on knowledge and perceptions of asthma among the secondary school students over a period of time.

\section{Hypotheses}

The following null hypotheses were tested in this study:

1. $\mathrm{H}_{0}$ : There would be no significant differences between pre-test and post-test knowledge scores among the participants (intervention) who receive the health education programme intervention and participants (control) who did not receive the health education programme intervention

2. $\mathrm{H}_{0}$ : There would be no significant differences between pre-test and post-test perceptions scores among the participants who receive the health education programme intervention and the participants (control) who did not receive the health education programme intervention.

3. $\mathrm{H}_{0}$ : There would be no significant change over time from pre-test to post-test 3 (6 weeks) (follow up) knowledge about asthma in the intervention group and no significant change over time from pre- test to post-test (follow up) in the knowledge about asthma in the control group.

4. $\mathrm{H}_{0}$ : There would be no significant change over time from pre-test to post-test 3(6 weeks) (follow up) perceptions about asthma in the intervention group and no significant change over time from pre-test to post-test (follow up) perceptions about asthma in the control group.

\section{Inclusion criteria}

To be included in the study participants must be students aged 9 to 19 years in the selected schools in Ile- Ife whom the parents or guardian gave an informed consent. They must not have also been previously diagnosed by a Physician as asthmatics and must not be on any asthma medications.

\section{Exclusion criteria}

Any students with asthma and or on treatment for asthma and those students whose parents or guardian failed to give informed consent were excluded from the study.

\section{Literature review}

It has been suggested that education of health care providers and the public is a vital element of the response to the challenge posed by asthma (Braman, 2006; Ndiaye et al, 2004). Asthma education and prevention remains the greatest opportunity for decreasing asthma incidence and mortality (Kintner et al, 2015). Studies have also shown that health education can enhance knowledge, change attitudes and behaviours (Daboer et al, 2008). In a study by Shaw et al, 2005, health education intervention program was tested in a non-equivalent control group design among a sample of 122 high school students recruited from two public schools out of which 19 were doctor diagnosed asthmatics who completed the study. Asthma severity classification was not reported. The asthma education program was given to the intervention school one week after collecting baseline data. The efficacy of the program was evaluated at 1 week, 3 weeks, and 6 weeks after given the asthma education intervention based on multiple variables including asthma knowledge, attitudes, self-efficacy, paediatric asthmarelated quality of life, and self-management behaviours. The result showed that self-efficacy perception demonstrated minimal improvements over time. Butz et al. (2005) conducted a four hour 
education programme which was delivered over two sessions to children with asthma to evaluate its effectiveness in improving knowledge of asthma, self-efficacy, and health-related quality of life. After 10 months, children in the intervention group reported higher mean scores on asthma knowledge $($ mean=12.45) than those in the control group (mean 10.8) $\mathrm{p}<0.001)$. Also, Kintner and Sikorskii (2009) tested the efficacy of a school-based academic (teaching) and counselling programme for 60 children from grades 4 to 6 in the USA (intervention $n=38$, control $n=22)$ ). The study showed an improvement in children's asthma knowledge with significant difference between children who received the programme and those who did not $(\mathrm{p}<0.01)$. In another study by Bowen, 2013, 32 children (intervention group $n=15$, control group $n=17$ ) formed the sample. The intervention was the modified Open Airway for Schools (OAS) programme. In this course, children (aged 8-11 years) were instructed in physiology of asthma, detecting warning signs of asthma, device use, and avoidance of triggers. It was conducted as weekly 90 minutes sessions for three weeks. Asthma Control Test, Paediatric Asthma Quality of Life Questionnaire, and Spirometry Machine were used to measure outcomes. The findings showed that the baseline knowledge score in the intervention group was $70 \%$ which was significantly increased to $80 \%$ at first follow up and to $90 \%$ in the second follow up compared to $50 \%$ in the control group ( $\mathrm{F}=19.028, \mathrm{P}<0.001$ ). Velsor-Friedrich et al., (2004) also reported that children in the intervention group that attended an asthma education programme showed a significant improvement in self-efficacy scores measured by the Asthma Belief Survey. The baseline score was 4.03, SD 0.10, which increased significantly to 4.23, SD 0.10 after five months $(\mathrm{p}=0.046)$. Children in the intervention group had a higher self-efficacy perception score and improved self-management practice which correlated with improved asthma control. Butz et al. (2005) also acknowledged a significant improvement in children's self-efficacy after implementing an asthma education programme (mean score change +2.62 , SD 6.3, $\mathrm{p}=0.005$ ). Knowledge is defined as the expertise and skills acquired by a person through experience or education with the ability to use it for a particular purpose (Sharda \& Shetty, 2008). Perception is the elaboration, interpretation and assignment of meaning to a sensory experience (Promtussananon, 2003). Illness perceptions are the cognitive representations or beliefs that patients or a healthy individual have about illnesses and medical conditions such as asthma (Moss-Morris et al, 2002).

\section{Methods}

\section{Research design, study area and population}

This study was a quasi- experimental design conducted among secondary school students in IleIfe, Osun State, South- West, Nigeria between September and December 2017 of the 2017/ 2018 academic year. Ile-Ife is an ancient city of Yoruba land situated in Osun State which is located in the South- Western part of Nigeria. There are four local governments which are affiliated with this city. They include Ife Central, Ife East, Ife North and Ife South Local Government Areas. The study areas were selected secondary schools in Ife Central Local Government Area as the intervention group and selected secondary schools in Ife North Local Government Area as the control group. The study population consisted of the secondary school students' boys and girls in the junior secondary school one, two and three (JSS1, JSS 2 and JSS 3) and senior secondary school one, two and three (SSS1, SSS2 and SSS3) of the selected schools.

\section{Ethical consideration}

Ethical approval to conduct the study was obtained from Obafemi Awolowo University Teaching Hospital Ethics and Research Committee (Protocol number ERC/ 2017/08/14; International registration number IRB/IEC/0004553; National registration number NHREC/27/02/2009a). Permission to conduct the study was sought and obtained from the State Ministry of Education zonal office and the school authority (Principals) of all the schools used for the study. Informed consent was also obtained from the respondents and their parent(s)/ guardian before proceeding with the study.

\section{Sample size determination}

The minimum sample size was calculated using the formula for the comparison of proportions of two independent groups which is given by the formula: 


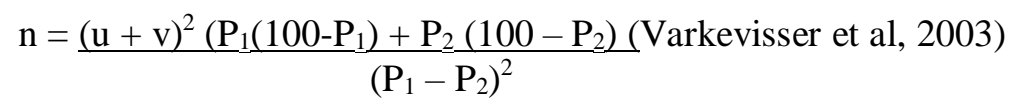

Where: $\mathrm{n}=$ Minimum required sample size, $\mathrm{P}_{1}=$ Estimated proportion of secondary school students who had good level of knowledge of asthma before intervention (44\%) (Shaw et al, 2005). $\mathrm{P}_{2}=$ Estimated proportion of secondary school students who had good level of knowledge of asthma after intervention. (62\%) (Shaw et al, 2005). $u=$ the critical value corresponding to power of the study at $80 \%=0.84 . \mathrm{V}=$ percentage of the normal distribution corresponding to the significance level (at $5 \%$ significance level, $\mathrm{v}=1.96$ for two sided significance).

$$
\mathrm{n}=\frac{(1.96+0.84)^{2}(44(100-44)+62(100-62)}{(62-44)^{2}}
$$

The minimum sample size calculated was $\mathbf{n = 1 1 7}$. To compensate for non- responses, misplaced or improperly completed questionnaires and attrition, the calculated sample size was increased by $20 \%$. One hundred and eighty (180) questionnaires were administered to each of the Intervention and Control groups eventually.

\section{Sampling method}

The sampling technique was a multistage sampling technique. The first stage was the selection of the intervention and control groups from the four local government areas in Ile- Ife, Nigeria. Two local government areas were selected from the four local government areas in Ile Ife using simple random sampling. They are Ife Central and Ife North local government areas. Each of the two local government areas were assigned to either intervention or control group through the process of simple balloting. Ife Central Local Government area was the intervention group while Ife North Local Government area was the control group. The two local government areas are far apart enough to minimize contamination of the control group by the intervention group. The second stage consisted of selection of 3 wards from the wards in each local government study site (Ife Central LGA has 11 wards and Ife North LGA has 10 wards) using convenience sampling technique. The third stage was the selection of one school from each ward making a total of three schools from each study site by simple random technique. The last stage consisted of the selection of at least sixty students from each school to make a total of 180 secondary school students as participants for each group based on the study criteria using purposive sampling technique.

\section{Data collection}

Data for this quasi- experimental study was collected using a pre-tested 71- item, purpose designed, self- administered anonymous questionnaire containing closed ended questions to assess the knowledge and perceptions of asthma among these secondary school students in Ile- Ife, South-West, Nigeria. The content validity and content validity index analysis for the two instruments to test the outcomes measures of knowledge and perceptions (using modified Newcastle asthma knowledge questionnaire (NAKQ) and modified revised illness perception questionnaire (IPQ-R)) were first done by the appointment of six panel members who rated the items in the questionnaire. After the content validity processes of the questionnaire, it was then pre-tested among thirty secondary school students in a school in Ife East local government area with a view to detecting deficiencies or ambiguities in the questionnaires, making appropriate corrections and finding its reliability among the study population. The questionnaire requires approximately 25 minutes to be completed. The Cronbach's Alpha for both scales from the pilot testing were measured and revealed high internal consistency values in modified NAKQ (0.627) and adapted modified IPQ-R (0.718) as confirmed by Polit and Beck, 2008; Sekaran, 2006. The questionnaire contained three sections. The first section contained 10 items focusing on socio-demographic characteristics of the secondary school students. The second section which is a modified Newcastle asthma knowledge questionnaire adapted for the study population is an instrument which consists of 31 questions (31 true/false items/ I don't know answer) and investigated respondents' general knowledge of asthma, knowledge of recognition, triggers and management of acute asthma, maintenance treatment and false myths about asthma. The third section which is a modified Revised illness perception questionnaire (IPQ-R) which have been adapted to assess illness perceptions among healthy people (Figueiras and Alves, 2007) is an instrument which 
consists of 30 questions (30 Yes/No/ Not sure answers) and contained statements regarding asthma perceptions in which the respondents were asked to indicate whether in each case they agree with the statement or not, or they are not sure. Answers were graded by assigning 1 point for the right answers and 0 point for the wrong answers given to the questions on asthma knowledge. Scores regarding asthma knowledge range from 0 to 31. To measure the level of students' knowledge in percentage, the total score is divided by 31 points and multiplied by 100 . Scores regarding perceptions of asthma range from 0 to 30 . To measure the level of students' perceptions in percentage, the total score is divided by 30 points and multiplied by 100 . The health education programme was for a period of two weeks. The first data collection was the baseline (pre- test) data. It was collected from the control group and the intervention group. This was collected one week prior to the health education intervention which was given to the intervention group. This was followed by delivering of health education programme to the intervention group participants across the 3 selected schools in Ife Central Local Government Area for the period of two weeks. The second data was collected from the intervention group at post- test date (1 week). The third data was collected from the intervention group at post- test date ( 3 weeks). The fourth data was collected from the intervention group at posttest date (6 weeks) and also from the control group at post- test date (6 weeks) for their second data. This was then followed by delivery of health education programme to the control group participants after the research study had been completed to compensate them. The reasons for selecting these intervals is based on a similar study conducted by Shaw et al, 2005 where the outcomes being tested were measured at the post intervention dates (1, 3 and 6 weeks) in the intervention group and also Social Cognitive Theory which confirmed that observing young person's behavioural change should occur after a short period of time (at least 3 weeks) to assess the point of maximum benefits where learning by observation will be intensified. Over this first three weeks, the students will be assumed to follow the process of learning by observation (attention, retention, and motivation). However, the last assessment post intervention ( 6 weeks later) was aimed to assess students' ability to retain the acquired learning over a short period of time. The outcomes could still be measured over an extended period of time but this present study was however limited to 1,3 and 6 weeks post intervention date in the intervention group. The intervention sessions of health education on asthma which are components of Health Belief Model (HBM) were in form of interactive lectures using Microsoft PowerPoint ${ }^{\circledR}$ presentations with a projector, use of posters, focused group discussions and practical sessions on the use of peak flow meters and inhalers. The curriculum for the health education on asthma included provision of adequate information to these students on the modules of general knowledge of asthma aetiology, epidemiology and physiology of asthma, identification of common triggers of asthma and how to control these triggers, types of asthma medications, and asthma management, and exercise and asthma, prognosis of asthma and myths about asthma which were delivered using Microsoft PowerPoint ${ }^{\circledR}$ lectures (equipped with speaker's notes and formatted on zip disks), activity hand-outs, discussion dialogues, examination with answer keys, case studies, and resource lists. Similar to the learning activities in these interventions, components of social cognitive theory (SCT) such as performance accomplishments, vicarious experience, verbal persuasion and emotional arousal were also incorporated into the asthma health education programme to enhance the self-efficacy perceptions of the secondary school students.

\section{Data analysis}

The completed questionnaires were collated, analyzed and presented using descriptive statistics. Means, percentages, and standard deviations (SD) were used to describe the distribution of demographics between the study groups (control Vs. intervention) and over study stages (pre-test, post-test I, post- test II and post- test III). Inferential statistics of Paired sample t-tests were conducted to examine differences between pre-test and post-test scores in the intervention and the control groups. Also one-way ANOVA repeated measures tests were utilised to measure the change over time in each of the groups' knowledge, and then perceptions of asthma of the secondary school students. Statistical level of significance was set at P- value $<0.05$. All statistical analyses were performed using the Statistical Package for the Social Sciences, Version 20.0 (IBM, Armonk, NY, USA). 


\section{Results}

One hundred and sixty two (162) participants completed the study in the Intervention group (a 90\% completion rate) and 153 participants completed the study in the Control group (an 85\% completion rate).

\section{Demographic characteristics of the participants}

The sample consisted of secondary school students $(n=315)$. Table 1 below shows the distribution of the participants. It showed there were more female respondents among the control group compared with intervention group than male. Majority of the respondents (59.05\%) were in the 13-16 years age group. Also, Classes SSS 1 and SSS 2 had most respondents with fifty seven (18.1\%) each. Largest percentages of the respondents were Christians (92.06\%) as shown by the result. The result also showed that largest percentages of them were Yoruba tribe (93.02\%).

Table 1. Demographic characteristics of the participants

\begin{tabular}{|c|c|c|c|}
\hline \multirow{2}{*}{$\begin{array}{l}\text { Participants' } \\
\text { Characteristics }\end{array}$} & \multicolumn{2}{|l|}{ Study Groups } & \multirow{2}{*}{ Total } \\
\hline & $\begin{array}{l}\text { Intervention Group } \\
(\mathbf{n}=162) \mathbf{n}(\%)\end{array}$ & $\begin{array}{l}\text { Control Group } \\
(n=153) \text { n (\%) }\end{array}$ & \\
\hline $\begin{array}{l}\text { Gender } \\
\text { Male } \\
\text { Female }\end{array}$ & $\begin{array}{l}81(50.0) \\
81(50.0)\end{array}$ & $\begin{array}{l}64(41.8) \\
89(58.2)\end{array}$ & $\begin{array}{l}145 \\
170\end{array}$ \\
\hline $\begin{array}{l}\text { Age Group } \\
9-12 \\
13-16 \\
17-20\end{array}$ & $\begin{array}{l}59(36.4) \\
95(58.6) \\
8(4.9)\end{array}$ & $\begin{array}{l}35(22.9) \\
91(59.5) \\
27(19.6)\end{array}$ & $\begin{array}{l}94 \\
186 \\
35\end{array}$ \\
\hline $\begin{array}{l}\text { Class level } \\
\text { JSS } 1 \\
\text { JSS } 2 \\
\text { JSS } 3 \\
\text { SSS } 1 \\
\text { SSS } 2 \\
\text { SSS } 3 \\
\end{array}$ & $\begin{array}{l}23(14.2) \\
29(17.9) \\
30(18.5) \\
27(16.7) \\
27(16.7) \\
26(16.0) \\
\end{array}$ & $\begin{array}{l}20(13.1) \\
27(17.6) \\
25(16.3) \\
30(19.6) \\
24(15.7) \\
27(17.6) \\
\end{array}$ & $\begin{array}{l}43 \\
56 \\
55 \\
57 \\
51 \\
53\end{array}$ \\
\hline $\begin{array}{l}\text { Religion } \\
\text { Christianity } \\
\text { Islam } \\
\text { Others }\end{array}$ & $\begin{array}{l}151(93.2) \\
11(6.8) \\
-\quad\end{array}$ & $\begin{array}{l}140(91.5) \\
12(7.8) \\
1(0.7)\end{array}$ & $\begin{array}{l}290 \\
23 \\
1\end{array}$ \\
\hline $\begin{array}{l}\text { Ethnic Groups } \\
\text { Yoruba } \\
\text { Igbo } \\
\text { Hausa } \\
\text { Others } \\
\end{array}$ & $\begin{array}{l}143(88.3) \\
13(8.0) \\
1(0.6) \\
5(3.1) \\
\end{array}$ & $\begin{array}{l}150(98.0) \\
1(0.7) \\
- \\
2(1.3) \\
\end{array}$ & $\begin{array}{l}293 \\
14 \\
1 \\
7 \\
\end{array}$ \\
\hline
\end{tabular}

\section{Demographic characteristics of the respondents in relation to asthma}

The result showed in table 2 below that $42(13.3 \%)$ of the respondents have a relative with asthma. The results also showed that $113(35.9 \%)$ have lived or known someone with asthma. Two hundred and forty $(76.2 \%)$ of the respondents had heard about asthma before. Television and Radio constituted the largest source of information about asthma accounting for $30.2 \%$ of all the responses. These were followed by School (16.8\%), with Doctor or Healthcare Practitioner accounted for the least source of Information (6.3\%). 
DOI: $10.21522 /$ TIJPH.2013.06.01.Art011

ISSN: $2520-3134$

Table 2. Demographic characteristics of the respondents in relation to asthma

\begin{tabular}{|l|l|l|l|}
\hline Characteristics & \multicolumn{2}{|l|}{ Total } \\
\cline { 2 - 3 } & $\begin{array}{l}\text { Intervention Group } \\
(\mathbf{n = 1 6 2}) \mathbf{n}(\boldsymbol{\%})\end{array}$ & $\begin{array}{l}\text { Control } \\
\text { Group } \\
(\mathbf{n = ~ 1 5 3 )} \mathbf{n} \\
\mathbf{( \% )}\end{array}$ & \\
\hline $\begin{array}{l}\text { Family Experience 1 } \\
\text { (Have a relative with }\end{array}$ & $24(14.80)$ & $18(11.80)$ & 42 \\
asthma) & $138(85.20)$ & $135(88.20)$ & 273 \\
Yes & & & \\
No & & & \\
\hline Family experience 2 & & $39(25.50)$ & 113 \\
(Have lived with or & $74(45.70)$ & $114(74.50)$ & 202 \\
known someone with & $88(54.30)$ & & \\
asthma) & & & \\
Yes & & $95(62.10)$ & 240 \\
No & & $58(37.90)$ & 75 \\
\hline $\begin{array}{l}\text { Awareness of asthma } \\
\text { Yes }\end{array}$ & $145(89.50)$ & $27(17.65)$ & 53 \\
No & $17(10.50)$ & $54(35.29)$ & 95 \\
\hline $\begin{array}{l}\text { Sources of knowledge } \\
\text { about asthma? }\end{array}$ & $26(16.05)$ & $16(10.46)$ & 29 \\
School & $41(25.31)$ & $12(7.84)$ & 32 \\
TV \& Radio & $13(8.02)$ & $8(5.23)$ & 25 \\
Books & $20(12.35)$ & $5(3.27)$ & 22 \\
Relatives \& Family & $17(10.49)$ & $6(3.92)$ & 20 \\
Friends & $17(10.49)$ & $25(16.34)$ & 39 \\
Newspaper \& & $14(8.64)$ & & \\
Magazine & $14(8.64)$ & & \\
Doctor/ Healthcare & & \\
Practitioner & & \\
Others & & & \\
\hline
\end{tabular}

\section{Knowledge test results}

Table 3 showed the paired sample t-test of the pre-test and post-test knowledge scores in the intervention and control groups. The increase in the mean level of knowledge between the pre-test and the post-test stage of the intervention group was 29 , which indicated an increase of $67.22 \%$ and was statistically significant $(\mathrm{t}(161)=-18.551, \mathrm{p}=0.000)$. The decrease in the mean level of knowledge between the pre-test and the post-test stage of the control group was 0.28 , which indicated a decrease of $0.63 \%$ and was statistically not significant $(\mathrm{t}(152)=0.184, \mathrm{p}=0.855)$.

Table 3. Comparisons of changes in knowledge scores in the intervention and control groups

\begin{tabular}{|l|l|l|l|l|l|l|}
\hline Group & N & $\begin{array}{l}\text { Pre-test } \\
\text { mean } \pm \text { SD }\end{array}$ & $\begin{array}{l}\text { Post-test } \\
\text { mean } \pm \text { SD }\end{array}$ & T & df & $\begin{array}{l}\text { Sig (2 } \\
\text { tailed) }\end{array}$ \\
\hline Intervention & 162 & $43.14 \pm 15.71$ & $\begin{array}{l}72.14 \pm \\
14.06\end{array}$ & -18.551 & 161 & $0.000^{*}$ \\
\hline Control & 153 & $44.66 \pm 14.58$ & $\begin{array}{l}44.38 \pm \\
14.83\end{array}$ & 0.184 & 152 & 0.855 \\
\hline
\end{tabular}




\section{Perception test results}

Table 4 showed the paired sample t-test of the pre-test and post-test perceptions scores in the intervention and control groups. There was an increase in the mean of 14.68 which represented a $27.85 \%$ increase in perceptions scores of the intervention group following health education programme and was statistically significant $(\mathrm{t}(161)=-3.774, \mathrm{p}=0.000)$. There was a decrease in the mean of 0.29 which represented a $0.55 \%$ decrease in perceptions scores in the control group who did not receive health education programme after 6 weeks but was not statistically significant $(\mathrm{t}(152)=$ $0.193, \mathrm{p}=0.848)$.

Table 4. Comparisons of changes in perceptions scores in the intervention and control groups

\begin{tabular}{|l|l|l|l|l|l|l|}
\hline Group & $\mathbf{n}$ & $\begin{array}{l}\text { Pre-test } \\
\text { mean } \pm \text { SD }\end{array}$ & $\begin{array}{l}\text { Post-test } \\
\text { mean } \pm \text { SD }\end{array}$ & t & df & $\begin{array}{l}\text { Sig (2 } \\
\text { tailed) }\end{array}$ \\
\hline Intervention & 162 & $52.72 \pm 48.98$ & $67.40 \pm 13.69$ & -3.774 & 161 & $0.000^{*}$ \\
\hline Control & 153 & $53.05 \pm 15.22$ & $52.76 \pm 15.40$ & 0.193 & 152 & 0.848 \\
\hline
\end{tabular}

\section{Repeated measures knowledge levels for the intervention and control groups}

Table 5 shows that the participants in the intervention group improved their knowledge scores over time. The results of Mauchly's test were significant $(X 2(2)=107.364, p=0.000)$, which violated the assumption of sphericity. Consequently, the Greenhouse-Geisser corrected value of $F$ was used to determine significance. The results of repeated measures ANOVA indicated that the knowledge levels of participants in the intervention group were affected over time $(F(2.027,326.391)=231.804$, $\mathrm{p}=0.000$ ). Figure 1 shows the unweighted means of knowledge for the intervention group calculated to control for the effect of other variables. The results are consistent with the findings and the plot shows that the level of knowledge of the intervention group significantly increased at the post-test stage, slightly decreased compared to post-test at post-test 2 stages and continued to increase up until the post-test 3 stage. Also Table 6 indicates that the participants in the control group had higher knowledge scores at the onset of the study than the post- test knowledge scores six weeks after participating in the study. The results of Mauchly's test were not considered because it was repeated over two measurements. Therefore the Greenhouse-Geisser corrected value of $\mathrm{F}$ was used to determine significance. The results of repeated measures ANOVA, indicated that the knowledge levels of participants in the control group were affected over time but was not statistically significant $(\mathrm{F}(1,152)=0.034, \mathrm{p}=0.855)$. Figure 2 shows the unweighted means of knowledge for the control group calculated to control for the effect of other variables. The plotted results show that the level of knowledge of the control group decreased significantly at the post-test stage. The final level of knowledge ended at a point lower than at the beginning.

Table 5. Repeated knowledge statistics for intervention group

\begin{tabular}{|l|l|l|}
\hline Knowledge test scores & N & mean \pm SD \\
\hline Pre-test & 162 & $43.14 \pm 15.71$ \\
\hline Post-test & 162 & $72.14 \pm 14.06$ \\
\hline Post-test 2 & 162 & $69.89 \pm 16.07$ \\
\hline Post-test 3 & 162 & $70.01 \pm 14.24$ \\
\hline
\end{tabular}

Greenhouse-Geisser; $\mathrm{F}=231.804(\mathrm{df}=2.027,326.391), \mathrm{p}=0.000$ 


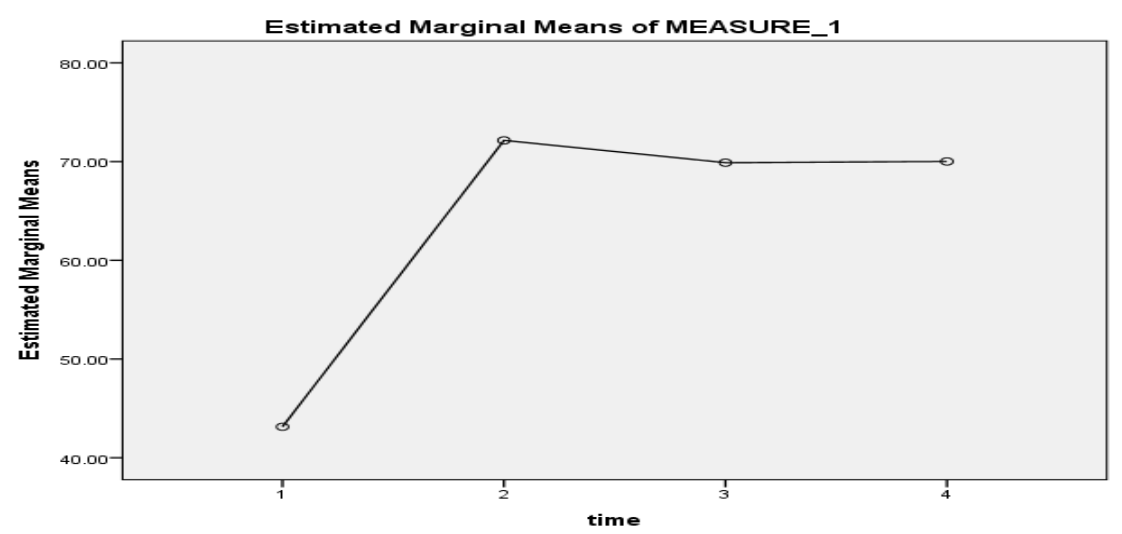

Figure 1. Mean plot of knowledge scores for the intervention group

Table 6. Repeated knowledge statistics for control group

\begin{tabular}{|l|l|l|}
\hline Knowledge test scores & $\mathbf{N}$ & mean \pm SD \\
\hline Pre-test & 153 & $44.66 \pm 14.58$ \\
\hline Post-test & 153 & $44.38 \pm 14.86$ \\
\hline
\end{tabular}

Greenhouse-Geisser; $\mathrm{F}=0.034(\mathrm{df}=1.000,152.000), \mathrm{p}=0.855$

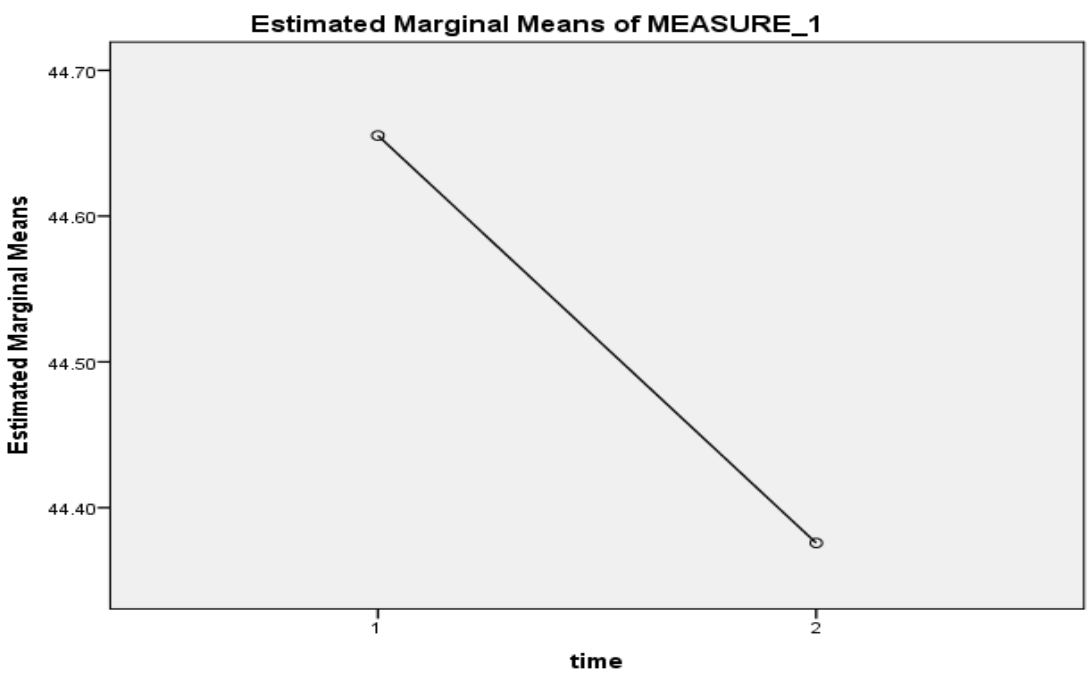

Figure 2. Mean plot of knowledge scores for the control group

\section{Repeated measures perceptions levels for the intervention and control groups}

Table 7 shows that the participants in the intervention group improved their perceptions overtime. The results of Mauchly's test were significant, X2(2) $=536.936, p=0.000$, which violated the assumption of sphericity. Therefore the Greenhouse-Geisser corrected value of $F$ was used to determine significance. The results of repeated measures ANOVA indicated that the perceptions levels of participants in the intervention group were affected overtime and were statistically significant $(\mathrm{F}(1.164,187.454)=12.830, \mathrm{p}=0.000)$. Figure 3 shows the unweighted means of perceptions for the intervention group calculated to control for the effect of other variables. The plotted results show that the estimated marginal means of perceptions significantly increased up until the post-test stage, slightly decreased at the post-test stage 2 and increased again at the post-test 3 stage, scores remaining much improved on the pre-test score. Table 8 indicates that the participants in the control group had higher perceptions scores at the onset of the study than the post- test perceptions scores six weeks after participating in the study. The results of Mauchly's test were not considered because the measurements were repeated over two measurements. Therefore the Greenhouse-Geisser corrected value of $\mathrm{F}$ was used to determine significance. The results of repeated measures ANOVA, 
indicated that the perceptions levels of participants in the control group were affected over time but was not statistically significant $(\mathrm{F}(1,152)=0.037, \mathrm{p}=0.848)$. Figure 4 shows the unweighted means of perceptions for the control group calculated to control for the effect of other variables. The plotted results show that the level of perceptions of the control group decreased significantly at the post-test stage. The final level of perceptions ended at a point lower than at the beginning.

Table 7. Repeated perceptions statistics for intervention group

\begin{tabular}{|l|l|l|}
\hline $\begin{array}{c}\text { Perceptions test } \\
\text { scores }\end{array}$ & N & mean \pm SD \\
\hline Pre-test & 153 & $52.72 \pm 48.98$ \\
\hline Post-test & 153 & $67.40 \pm 13.69$ \\
\hline Post-test 2 & 153 & $66.57 \pm 15.30$ \\
\hline Post-test 3 & 153 & $67.69 \pm 14.60$ \\
\hline
\end{tabular}

Greenhouse-Geisser; $\mathrm{F}=12.830(\mathrm{df}=1.164,187.454), \mathrm{p}=0.000$

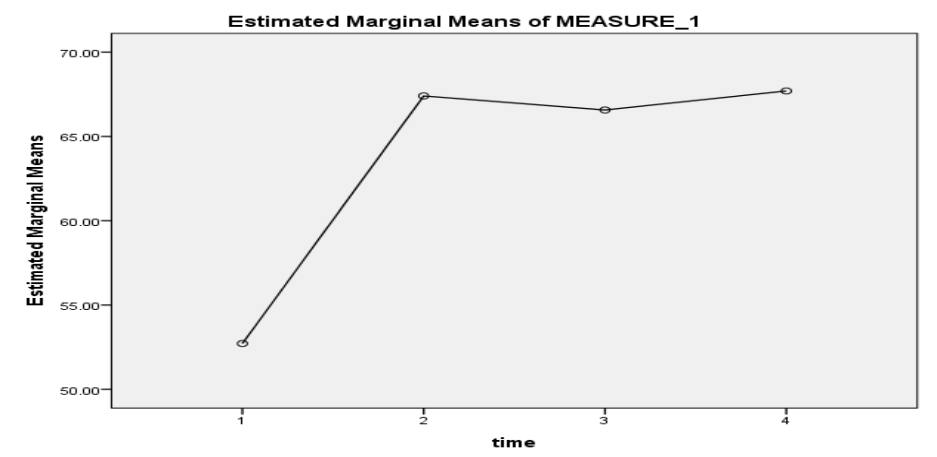

Figure 3. Mean plot of perceptions scores for the intervention group

Table 8. Repeated perceptions statistics for control group

\begin{tabular}{|l|l|l|}
\hline Perceptions test scores & N & mean \pm SD \\
\hline Pre-test & 153 & $53.05 \pm 15.22$ \\
\hline Post-test & 153 & $52.76 \pm 15.40$ \\
\hline
\end{tabular}

Greenhouse-Geisser; $\mathrm{F}=0.037(\mathrm{df}=1.000,152.000), \mathrm{p}=0.848$

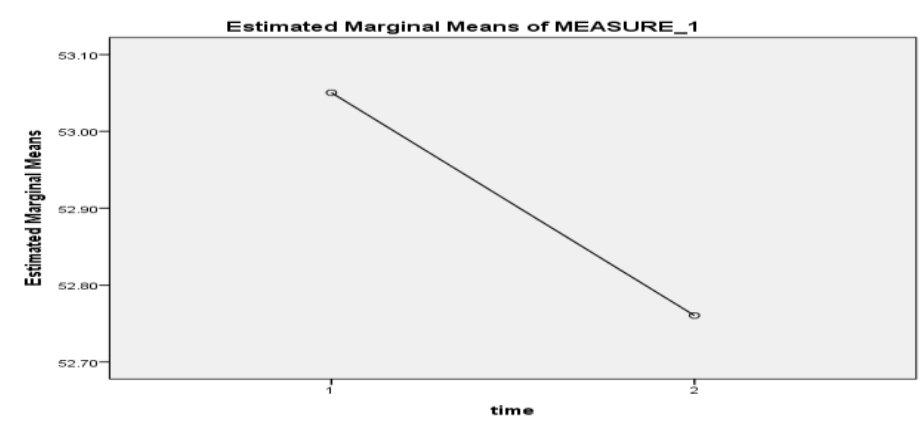

Figure 4. Mean plot of perceptions scores for the control group

\section{Discussion}

This study was conducted to determine the effect of asthma health education programme on knowledge and perceptions of asthma among secondary school students in Ile- Ife, Nigeria.

The sex distribution in this study had more female participants than male participants. This result is also similar to the study conducted by Shaw et al (2005) which reported female participants higher in number than male participants. This can be explained also that girl- child education is given an utmost priority among the study population. The result also showed higher Christian participants and Yoruba participants than any other religion and tribes respectively. This result can be explained by the fact that the sampled study population reflects the dominant religion being practiced in the communities 
and they are located in Yoruba land. This invariably shows that the study environment will usually reflect the characteristics of the study population. The result also showed that more participants in the intervention group have more family experiences and have heard about asthma more than the control group. This can be explained by the fact that prevalence of asthma is likely to be more in the urban/ semi- urban community which the population in the intervention group belongs than in the rural communities which the control group participants belong. This is corroborated by a study done by Pesek et al (2010) and Falade et al (2009).

\section{Effect of health educational intervention on knowledge of asthma among the secondary school students}

The result of this study showed that there was a significant difference in the pre- test and post- test knowledge scores of the secondary school students in the intervention group following health education programme intervention. The knowledge score increased from 43.14 to 72.14 that was $67.24 \%$ increase. On the other hand, the result of this study showed that there was no significant difference in the participants' pre- test and post- test knowledge scores in the control group (who did not receive health education programme intervention). The secondary school students from the intervention schools recorded significant improvement in their knowledge of asthma compared to the secondary school students in the control group after the health education intervention. Therefore, the improvement in knowledge of asthma obtained from this study could be attributed to the effect of health education administered on the secondary school students in the intervention group. This reflects both the quality of the materials used in the classes and high reflective adherence to the study manuals which were given to them after the health education intervention. The result of this study is in agreement with a similar study by Shaw et al, 2005 where asthma knowledge score increased significantly from 43.96 to 62.23 showing a $41.56 \%$ increase among secondary school students who received health education intervention. The result of this study is also in agreement with a study by Gibson et al, 1998 where asthma knowledge score which was poor at baseline increased significantly post- intervention among asthmatic and non-asthmatic students. The result is also in agreement with a similar study by Desalu et al, 2013 where asthma knowledge level increased significantly from baseline to post- intervention among post basic nursing students. There was also no significant difference in the control group (who did not receive health education intervention) in the study. The result is also in agreement with a similar study by Bowen, 2013 where asthma knowledge level increased significantly from baseline $60 \%$ to $70 \%$ post- intervention score showing a $14.3 \%$ increase and with no significant difference in the control group who did not receive health education intervention. Other studies that are in agreement with the result of this study are (Al- Sheyab et al, 2012; Kintner and Sikorskii, 2009; Levy et al, 2006; Butz et al, 2005; Shegog et al, 2001) whose results showed that health education intervention significantly increased the knowledge score in the intervention group compared to the control group who did not receive the health education intervention.

\section{Effect of health educational intervention on perceptions of asthma among the secondary school students}

There was a significant difference between the pre- test and post- test perceptions scores of the secondary school students in the intervention group following health education programme. Their perceptions scores increased from 52.72 to 67.40 which represent a $27.85 \%$ increase. There was no significant difference in the participants' pre- test and post- test perceptions scores in the control group. It could be inferred from this result that the secondary school students in the intervention schools recorded significant improvement in their perceptions of asthma over the secondary school students in the control group after the health education intervention. Therefore, the improvement in perceptions of asthma obtained from this study could be attributed to the effect of health education administered on the secondary school students in the intervention group. A closely related study done by Velsor-Friedrich et al (2004) supported the outcome of this study. It was reported that participants in the intervention group that attended an asthma education programme showed a significant improvement in self-efficacy scores measured by the Asthma Belief Survey. The baseline score was 
4.03, SD 0.10 , which increased significantly to 4.23 , SD 0.10 after five months $(\mathrm{p}=0.046)$. Selfefficacy is a contextual-related judgment of personal ability to organize and execute a course of action to attain designated levels of performance (Chemers et al, 2001). Self-efficacy arises from performance accomplishments, vicarious experience, verbal persuasion, and physiological states all of which were employed in this study. Perceived self-efficacy represents the belief that one has the capability to change risky health behaviours by personal action. A closely related study done by Butz et al, (2005) also supported the outcome of this study. They reported that self- efficacy perceptions in the intervention group of rural early- adolescents of school age who received health education improved significantly after the health education in the intervention group. The result of this study is also in agreement with a closely related study by Shegog et al (2001) where the self-efficacy perceptions improved significantly post- intervention in those that received health education intervention.

\section{Changes in secondary school students' knowledge levels over a period of time for the intervention and control group}

The knowledge levels of participants in the intervention group were affected overtime. The results showed that there was a significant change in knowledge overtime for the participants in the intervention group, over a period of 1 week, 3 weeks and over a period of 6 weeks. The level of knowledge of the intervention group significantly increased at the post- test stage sustained at the post- test 2 and post- test 3 stages though slightly less than the immediate follow up. From this result, it can be inferred that the secondary school students experienced the greatest rise in knowledge retention one week after the intervention but still managed to maintain their knowledge levels even six weeks following health education. This outcome was supported by close related study conducted among high school adolescents using adolescent asthma education intervention on their knowledge of asthma. Their result showed that the baseline knowledge score of asthma among the participants was mean 7.64 which significantly increased to mean 16.44 at immediate post- intervention but declined to mean score 8.80 at the 5 week follow up in the intervention group (Zografos et al, 2010). The result was also in agreement with a similar study among early adolescents conducted by Bowen, 2013 which showed that the knowledge levels significantly improved overtime in the intervention group. The result of this study is also in agreement with a similar study by Horner et al (2008) which showed there was a significant improvement in asthma knowledge score overtime among rural adolescents. The result of this study is however, in contrast with a similar quasi-experimental study conducted in USA by Velsor-Friedrich et al (2004), to examine the effects of a school-based education programme on children's aged 8-13 years knowledge of asthma. Their results showed no significant improvement in levels of knowledge among the intervention group. The result of this study, on the other hand showed that there was no significant change in the knowledge of asthma in the control group. The level of knowledge of the control group decreased slightly but was not significant at the post- test stage compared to the beginning. This result was also in agreement with the study of Bowen, 2013 which showed that there was no significant improvement in the knowledge level overtime among the control group (who did not receive health education intervention).

\section{Changes in secondary school students' perceptions levels over a period of time for the intervention and control group}

The perceptions levels of participants in the intervention group were also affected overtime. The result showed that there was a significant change in perceptions over time in the intervention group. The level of perceptions significantly increased from pre- test stage to post- test stage to post- test 2 stage and up until post- test 3 stages. From this result, it can be inferred that the health education intervention was effective beyond the immediate period and that the secondary school students were able to sustain and improve on their levels of perceptions of asthma up to the period of six weeks. This therefore suggests that the effect of health education intervention on perceptions of asthma among these secondary school students has some lasting effect over a period of time. The result is in agreement with a similar study by Horner et al (2008) which showed that there was statistically significant improvement in self-efficacy perception overtime in the intervention group who received 
health education intervention. On the other hand, the result of this study showed that there was no significant change in the perceptions of asthma over time in the control group. The level of perceptions of the control group decreased slightly at the post- test stage at a point lower than at the beginning of the study. The result of the study by Horner et al (2008) also showed there was no significant improvement in the self-efficacy perception in the control group of rural adolescents who did not receive health education intervention.

\section{Limitation of the study}

This study is an example of an effective method in which researchers and school teachers incorporate an asthma health education program into a structured health education class. However, the competing demands for students' time during a typical school day posed problems during the conduct of the school-based study. Attrition during each follow-up phase could also have affected the study results. Reasons for diminishing sample size from baseline included: 1) absent during data collection, 2) possible voluntary refusal to complete questionnaire, or 3) absent during intervention, therefore follow-up data are not valid. These were handled by the increasing of the sample size at the onset of the study. Despite potential problems with attrition, the school-based environment is fitting for asthma research as well as other clinically based programs.

\section{Conclusion}

The outcome of this study reveals that there is significant difference between the pre and post- test asthma knowledge and perceptions scores of the secondary school students in the intervention group following health education programme intervention. The study also shows a significant improvement in knowledge and perceptions of asthma overtime for the participants in the intervention group. The study therefore has been able to establish that health educational intervention has significant positive effect on knowledge and perceptions of asthma among secondary school students in Ile- Ife, Osun State, South West, Nigeria.

\section{Recommendation}

Based on the findings in this study, the followings are therefore recommended:

1. There is a need to utilize the mass media more as a medium of advocacy for asthma education.

2. Primary prevention strategies should be encouraged to be taken to the community levels through the health education given to the students with a view to reduce the impact of some trigger factors which have the propensity to increase the incidence of asthma among them.

3. Further researches of this same type over a longer period of 6 months, 12 months and 24 months can be carried out to provide insight into whether a longer health education programme intervention could ensure better or permanent results.

\section{References}

[1]. Anwar, H., Hassan, N., Jaffer, N., Al Sadri, E (2008). Asthma knowledge among asthmatic school students. Oman Medical Journal. Volume 23. Issue 2. Pp 90-95.

[2]. Al-sheyab, N., Gallagher, R., Crisp, J., Shah, S (2012). "Peer-led education for adolescents with asthma in Jordan: a cluster randomized controlled trial," Pediatrics, vol. 129, no. 1, pp. e106-e112.

[3]. Bender, B.G (2007). Depression symptoms and substance abuse in adolescents with asthma. Ann Allergy Asthma Immunol. 99:319-324.

[4]. Bjorksten, B (2000). Unmet needs in the treatment of asthmatic children and adolescents: Clin Exp Allergy. 30: 73-76.

[5]. Bousquet, J., Mantzouranis, E., Cruz, A.A., Ait-Khaled, N., Baena-Cagnani, C.E., Bleecker, ER, et al (2010). Uniform definition of asthma severity, control, and exacerbations: document presented for the World Health Organization Consultation on Severe Asthma. J Allergy.

[6]. Bowen, F (2013). Asthma education and health outcomes of children aged 8 to 12 years. Clinical Nursing Research, 22(2): p. 172-185. 
[7]. Braman, S.S (2006). The global burden of asthma. Chest. 130:4S-12S.Medline:16840363 doi:10.1378/chest.130.1_suppl.4S.

[8]. Brook, U., Kishon, Y (1993). Knowledge and Attitude of Healthy High School Students toward Bronchial Asthma and Asthmatic Pupils. Chest. Volume 103. Issue 2. Pp 455-457. http://dx.doi.org/10.1378/chest.103.2.455.

[9]. Butz, A., Pham, L., Lewis, L. P., Lewis, C., Hill, K., Walker, J., \& Winkelstein, M. (2005). Rural Children with Asthma: Impact of a Parent and Child Asthma Education Programme. Journal of Asthma, 42(10), 813-821.

[10]. Cicutto, I., To, T., Murphy, S. (2013). A Randomized Controlled Trial of a Public Health Nurse-Delivered Asthma Program to Elementary Schools. Journal of School Health, 83, 876-884. doi: 10.1111/josh.12106.

[11]. Daboer, J.C., Ogbonna, C., Jamda, M.A (2008). Impact of health education on sexual risk behaviour of secondary school students in Jos, Nigeria. Niger J Med. 17 (3). 324- 329.

[12]. Desalu, O.O., Abdurrahman, A.B., Adeoti, A.O., Oyedepo, O.O (2013). Impact of Short-Term Educational Interventions on Asthma Knowledge and metered-dose Inhaler Techniques among Post Basic Nursing Students in Ilorin, Nigeria- Result of a Pilot study. Sudan JMS. Volume 8. Number 2. Pp 77-84.

[13]. Falade, A.G., Ige, O.M., Yusuf, B.O., Onadeko, M.O., Onadeko, B.O (2009). Trends in the prevalence and severity of symptoms of asthma, allergic rhinoconjunctivitis, and atopic eczema. J Natl Med Assoc. 101:414e8.

[14]. GINA (2014). Global Burden of Asthma Report. Global Initiative for Asthma, 2014.

[15]. Guo, S.E., Ratner, P.A., Johnson, J.L, et al (2010). Correlates of smoking among adolescents with asthma. J Clin Nurs. 19 (5-6):701-711.

[16]. Horner, S. D., Fouladi, R. T. (2008). Improvement of Rural Children's Asthma Self-Management by Lay Health Educators. The Journal of School Health, 78(9), 506-513. http://doi.org/10.1111/j.17461561.2008.00336.x

[17]. Kann, L., Telljohann, S.K., Wooley, S.F (2007). Health Education: Results from the School Health Policies and Programs Study 2006. Journal of School Health. Volume 77. Issue 8. Pp 408-434. DOI: 10.1111/j.1746-1561.2007.00228.x.

[18]. Kintner, E. K., Sikorskii, A. (2009). Randomized Clinical Trial Of A School-Based Academic And Counselling Program For Older School-Age Students. Nursing Research. 58. 321-331. Doi: 10.1097/NNR.0b013e3181b4b60e

[19]. Kintner, E., Cook, G., Marti, C.N., Stoddard, D., Gomes, M., Harmon, P., Van Egeren, L.A (2015). Comparative Effectiveness on Cognitive Asthma Outcomes of the SHARP Academic Asthma Health Education and Counselling Program and a Non-Academic Program. Res Nurs Health. 38(6):423-35. Doi: 10.1002/nur.21678.

[20]. Levy, M., Heffner, B., Stewart, T., Beeman, G. (2006). The Efficacy of Asthma Case management in an Urban School District in Reducing School Absences and Hospitalizations for Asthma. Journal of School Health. 76. 320-324.

[21]. Marsden, E.J., Somwe, W.S., Chabala, C., Soriano, J.B., Valles, C.P., Anchochea, J (2016). Knowledge and perceptions of asthma in Zambia: a cross- sectional survey. BMC Pulmonary Medicine. 16. 33. Doi: 10.1186/s 12890-016-0195-3.

[22]. Mcghan, S. L., Wong, E., Sharpe, H. M., Hessel, P. A., Mandhane, P., Boechler, V. L., Majaesic, C., Befus, A. D. (2010). A Children Asthma Education Program: Roaring Adventures Of Puff (Rap), Improves Quality Of Life. Canadian Respiratory Journal: Journal of the Canadian Thoracic Society. 17. 67.

[23]. Moss- Morris, R., Weinmann, J., Petrie, K., Horne, R., Cameron, L., Buick, D (2002). The revised illness perception questionnaire (IPQ-R). Psychology and Health. 17. 1-16. Doi: 10. 1080/08870440290001494.

[24]. Musa, B.M., M.D.A (2014). Asthma prevalence in Nigerian adolescents and adults: systematic review and meta-analysis. Afr J Respir Med. 10(1): 4-9.

[25]. Ndiaye, M., Ndir, M., Hane, A.A., Michel, F.B., Bousquet, J (2004). Application of the WHO chronic respiratory diseases programme in Sub-Saharan Africa: problems in Senegal [in French]. Rev Mal Respir. 21:479-91. Medline: 15292840. doi: 10.1016/S0761-8425(04)71352-2.

[26]. Oluwole, O., Arinola, G.O., Huo, D., Olopade, O.O (2017). Household biomass fuel use, asthma symptoms severity, and asthma under-diagnosis in rural school children in Nigeria: a cross- sectional observational study. BMC Pulmonary Medicine. 17: 3. Doi:10.1186/s12890-016-0352-8. 
DOI: 10.21522/TIJPH.2013.06.01.Art011

ISSN: 2520-3134

[27]. Pesek, R.D., Vargas, P.A., Halterman, J.S., Jones, S.M., McCracken, A., Perry, T.T (2010). A comparison of asthma prevalence and morbidity between rural and urban schoolchildren in Arkansas. Ann Allergy Asthma Immunol. 104(2):125-31.

[28]. Polit, D., Beck, C. T. (2008). Is There Gender Bias In Nursing Research? Research in Nursing \& Health, 31, 417-427.

[29]. Promtussananon, S (2003). Perceptions on physiopathology and preferred treatment of epilepsy and asthma in the Limpopo Province, South Africa. Health. SA Gesondheid. March, 2003. ISSN: 1025-9848.

[30]. Reddel, H.K., Taylor, D.R., Bateman, E.D., Boulet, L.P., Boushey, H.A., Busse, W.W., et al (2009). An official American Thoracic Society/ European Respiratory Society statement: asthma control and exacerbations: standardizing endpoints for clinical asthma trials and clinical practice. Am J Respir Crit Care Med. 180:59-99. Medline:19535666. doi:10.1164/rccm.200801-060ST.

[31]. Sekaran, U. (2006). Research methods for business: A skill building approach. John Wiley \& Sons. New York.

[32]. Sharda, A. J., Shetty, S. (2008). A comparative study of oral health knowledge, attitude and behaviour of first and final year dental students of Udaipur city, Rajasthan, India. Int J Dent Hyg. 6(4). 347-353. Doi: 10.1111/j.1601-5037.2008.00308.x.

[33]. Shaw, S., Marshak, H.H., Dyjack, D.T., Neish, C.M (2005). Effects of a Classroom-based Asthma Education Curriculum on Asthma Knowledge, Attitudes, Self-efficacy, Quality of Life, and Self-management Behaviours among Adolescents. American Journal of Health Education. Volume 36. No. 3. Pp 140- 145.

[34]. Shegog, R., Bartholomew, K., Parcel, G.S., Sockrider, M.M., Masse, L., Abramson, S.L (2001). Impact of a Computer assisted Education Program on Factors Related to Asthma Self-management Behaviour. Journal of the American Medical Informatics Association Volume 8. Number 1 .Pp 49- 61.

[35]. Thies, K.M., McAllister, J.W (2001). The health and education leadership project: a school initiative for children and adolescents with chronic health conditions. J Sch Health. 71: 167-172.

[36]. Towns, S.J., van Asperen, P.P (2009). Diagnosis and management of asthma in adolescents. Clin Respir J. 3:69-76.

[37]. Valeros, L., Kieckhefer, G., Patterson, D (2001). Traditional asthma education for adolescents. J Sch Health. 71: 117-119.

[38]. Varkevisser C. M., Pathmanathan I., Brownlee A (2003). Designing and conducting health systems research projects. KIT publishers and the International Development Research Center (IDRC). 2003.

[39]. Velsor-Friedrich, B., Pigott, T. D., Louloudes, A. (2004). The Effects of a School-Based Intervention on the Self-Care and Health of African-American Inner-City Children with Asthma. Journal of Pediatric Nursing. 19. 247-256.

[40]. Vos, T., Flaxman, A.D., Naghavi, M, et al (2013). Years lived with disability (YLDs) for 1160 sequalae of 289 diseases and injuries 1990-2010: a systematic analysis for the Global Burden of Disease Study 2010. Lancet. 380. 2163-2196. Doi:10.1016/S0140-6736 (12)61729-2.

[41]. WHO, 2012. (Fact sheets). Geneva, Switzerland: World Health Organization; 2012.

[42]. WHO, 2013. (Fact sheets). Geneva, Switzerland. World Health Organization; 2013.

[43]. Zografos, K., Marshak, H., Dyjack, D., Neish, C (2010). The effects of an adolescent asthma education intervention on knowledge, intention, behaviour, self-efficacy and self-consciousness. Californian Journal of Health Promotion. Volume 8. Issue 1. Pp 60- 71. 